UNIVERSITY OF GOTHENBURG

SCHOOL OF BUSINESS, ECONOMICS AND LAW

WORKING PAPERS IN ECONOMICS

No 445

\title{
Reconciling Pro-Social vs. Selfish Behavior \\ - Evidence for the Role of Self-Control
}

\author{
Peter Martinsson \\ Kristian Ove R. Myrseth \\ Conny Wollbrant
}

May 2010

ISSN 1403-2473 (print)

ISSN 1403-2465 (online) 


\title{
Reconciling Pro-Social vs. Selfish Behavior - Evidence for the Role of Self-Control
}

\author{
Peter Martinsson, University of Gothenburg ${ }^{A}$ \\ Kristian Ove R. Myrseth, ESMT European School of Management and Technology ${ }^{B}$ \\ Conny Wollbrant, University of Gothenburg ${ }^{C}$
}

\begin{abstract}
We test the proposition that individuals may experience a self-control conflict between short-term temptation to be selfish and better judgment to act pro-socially. Using a dictator game and a public goods game, we manipulated the likelihood that individuals identified self-control conflict, and we measured their trait ability to implement self-control strategies. Consistent with our hypothesis, we find that trait self-control exhibits a positive and significant correlation with pro-social behavior in the treatment that raises likelihood of conflict identification, but not in the treatment that reduces likelihood of conflict identification.
\end{abstract}

JEL Classification: D01, D03, D64, D70.

Keywords: self-control, pro-social behavior, altruism, experiment.

\footnotetext{
Acknowledgments: Financial support from the Swedish Research Council (Vetenskapsrådet) the Swedish International Development Cooperation Agency (Sida) to the Environmental Economics Unit at the University of Gothenburg and Jan Wallanders and Tom Hedelius Foundation is gratefully acknowledged. We are grateful to Fredrik Carlsson, Gary Charness, John Hey, Martin Kocher, Katarina Nordblom, Olof Johansson-Stenman, and Johan Stennek, to conference participants at SJDM 2009, ESA 2009, and IMEBE 2009, and to seminar participants at the University of Gothenburg for helpful comments and discussions. Horacio Antonio Villegas Rivera provided excellent logistical support and Angela Maria Gonzales provided excellent research assistance.

A Department of Economics, University of Gothenburg, Box 640, 40530 Gothenburg, Sweden; Ph +46 3178652 55; Fax +46 3178610 43; E-mail: peter.martinsson@economics.gu.se.

в ESMT European School of Management and Technology, Schlossplatz 1, 10178 Berlin, Germany; Ph +49 (0) 3021231 1529; Fax +49 (0) 30212311281 E-mail: myrseth@esmt.org

${ }^{\mathrm{C}}$ Department of Economics, University of Gothenburg, Box 640, 40530 Gothenburg, Sweden; Ph +46 3178626 15; Fax +46 3178610 43; E-mail: conny.wollbrant@economics.gu.se.
} 
Lured by temptation, individuals may find themselves acting against their better judgment. Self-control failure, famously termed “akrasia” in Plato’s Protagoras (Plato, 1986/B.C. 380) represents a central issue of both philosophy and modern-day social sciences. Problems of self-control persist throughout domains of our daily life. ${ }^{1}$ For example, the dieter faced with the opportunity to indulge in a delicious creamy cake may perceive a conflict between indulging and maintaining a good figure. The student may feel conflicted between the desire to go to the cinema and her better judgment to stay home and study (e.g. O’Donoghue and Rabin, 1999; Burger et al., 2009). And, similarly, the fashionista might feel conflicted between the temptation to purchase new boots and her better judgment to maintain a responsible budget.

Perhaps less intuitively, but no less importantly, the question of pro-social versus selfish behavior may be understood in similar terms. This conceptualization may help reconcile conflicting notions in economics of the selfish Homo Economicus and the pro-social Homo Behavorialis. That individuals should care much about their own self-interest seems almost tautological and requires little further exposition, but that individuals also should care about the interests of others - even at the expense of those of their own - has attracted significant interest (for overview on social preference see e.g. Fehr and Schmidt, 2006). ${ }^{2}$ For example, many individuals voluntarily contribute to charity or to public goods (e.g. recycling), and they pay their taxes even though economic theory expects them not to, given low likelihood of punishment. ${ }^{3}$ Nonetheless, one could imagine that even individuals of pro-social inclination on occasion may feel tempted to act selfishly and hence underreport income to the authorities. That is, pro-social preferences potentially fly in the face of basic urges for personal gain - or greed - and the individual may thus experience a self-control conflict between better judgment to act pro-socially and temptation to act selfishly.

Only recently has the psychological literature started to explore how the question of prosocial versus selfish behavior relates to that of self-control. Loewenstein (1996; 2000) suggests that selfish behavior may be motivated by visceral urges or drive-states, resembling cravings for relief of hunger, pain, and sexual deprivation. O’Donaghue and Loewenstein (2007) argue that

\footnotetext{
${ }^{1}$ For work on self-control and time inconsistency, see e.g. hyperbolic and quasi-hyperbolic discounting models by Strotz (1955) and Laibson (1997), the "planner-doer" model by Thaler and Shefrin (1981), and the dual-self model by Fudenberg and Levine (2006).

${ }^{2}$ For pioneering work in this area see e.g., Kahneman et al., (1986a; 1986b).

${ }^{3}$ There exists an extensive literature on the motivation behind pro-social behavior. For example, Bénabou and Tirole (2006) classify the motivations into three broad categories: intrinsic, extrinsic and image motivation, and a similar classification is found in Ariely et al. (2009)
} 
such selfish urges often may conflict with the "colder," more abstract preferences for altruism, as visceral urges for sweets could conflict with more abstract preferences for a fine figure or good health. At present, there is but preliminary evidence for this idea. Most notably, Pronin et al. (2008) show that decisions about others resemble decisions about "future selves," both classes of which contrast to decisions about less abstract "present selves.” Moreover, Curry et al. (2008) find in a standard public goods game that individuals' discount rates are negatively associated with their contribution to the public good. That is, more "impatient” individuals contributed less to the public good than did "patient" ones. While indeed supportive of the hypothesis that the question of pro-social versus selfish behavior may represent a problem of self-control, existing empirical evidence is not conclusive.

In this paper we attempt a direct test of the hypothesis that pro-social versus selfish behavior may represent a self-control problem. In so doing, we rely on two conditions necessary for successfully exercising restraint in the face of temptation; Myrseth and Fishbach (2009) propose a two-stage model of self-control, which postulates that an individual in the face of temptation first identifies conflict or not between indulging and pursuing a higher-order goal and, second, that the individual next employs self-control strategies only if and only if conflict was identified at the first stage (see Figure 1). Such self-control strategies may take a variety of forms, and common examples include willpower (e.g., Baumeister et al., 1994), and pre-commitment (Thaler and Shefrin, 1981; Schelling, 1984). Critically, self-control strategies are relevant to the decision to indulge only when the individual has identified self-control conflict. Therefore, one strategy for investigating whether the problem of pro-social versus selfish behavior resembles one of self-control is to test whether self-control strategies are positively associated with prosocial behavior when individuals have identified self-control conflict, but less so or not at all when individuals have not.

(Figure 1)

Determinants of conflict identification in the face of temptation have been explored only recently. In some contexts, the question is almost trivial and identification of conflict virtually obvious. For example, the diabetic dieter probably knows that having even a single, tempting chocolate may incur major costs. However, the question of self-control conflict is more 
ambiguous for the non-diabetic dieter who faces the same chocolate. Having this one chocolate alone will not incur major costs, but doing so regularly might. Similarly, the good citizen may find that not reporting his annual income would represent a major threat to his self-image (and possibly also to his criminal record), but failing to report but a few small windfalls is a more ambiguous matter. Myrseth and Fishbach (2010) use the term epsilon cost temptation to denote tempting opportunities that incur nothing but trivial costs when consumed in small amounts but potentially serious costs when consumed extensively. They argue that individuals identify selfcontrol conflict in the face of epsilon cost temptation if and only if two conditions are met: (a) the focal consumption opportunity must be viewed in relation to multiple additional opportunities, and (b) the decision maker must assume that similar choices are made for each opportunity. That is, considering the question of whether or not to have a delicious creamy cake will evoke selfcontrol conflict in the dieter if the dining opportunity is viewed in relation to future opportunities for dessert consumption, but not if the dining opportunity is viewed in isolation, as a singular episode. Similarly, the question of whether or not to withhold from the tax authorities a few small amounts may elicit self-control conflict in the good citizen if the income reporting is viewed in relation to future reports, but not if the reporting is viewed in isolation.

Myrseth and Fishbach (2010) show that subtle framing manipulations are sufficient to influence identification of self-control conflict in the face of epsilon cost temptation. They find that presenting a calendar displaying the current month with a grid separating the dates increased participants' subsequent consumption of potato chips compared to participants whom were presented a non-gridded calendar of the current month. The reason for this, they argue, is that the gridded calendar activated an isolated (versus interrelated) frame of the choice opportunity; it made participants more likely to isolate the date in question and thus less likely to see the decision task in relation to similar future opportunities. Consequently, the grid reduced the likelihood that participants would identify a conflict between the temptation to have chips and long-term health or dieting goals. Indeed, participants who were viewing the gridded calendar reported that they experienced less conflict during their decision to have chips or not than did those who were viewing the non-gridded calendar. ${ }^{4}$ Furthermore, participants' trait ability to

\footnotetext{
${ }^{4}$ Experienced conflict was assessed by averaging participants' answers to two questions: (1) to what extent they felt mixed feelings when deciding whether or not to have more potato chips, and (2) to what extent they felt conflicted when deciding whether or not to have more chips. The questions were posed immediately after participants finished consuming potato chips.
} 
implement self-control strategies, measured by Rosenbaum's (1980) psychometric scale ${ }^{5}$, positively predicted chips consumption for those who were viewing the calendar without the grid (and who identified conflict) but not for others who were viewing the calendar with (and who were less likely to identify conflict). That is, participants who viewed the calendar without the grid, more likely than those who viewed the calendar with, identified self-control conflict and therefore leveraged their self-control strategies to resist the tempting chips.

To explore our hypothesis that the problem of pro-social versus selfish behavior may represent one of self-control, we have applied the empirical strategy from Myrseth and Fishbach (2010) in two classic experimental games: the dictator game and the public goods game. These games pit pro-social behavior against self-interest. If pro-social versus selfish behavior could represent a self-control conflict, we would expect participants' trait self-control, as measured by Rosenbaum's (1980) scale, to positively predict pro-social behavior for participants who had just previously viewed a calendar without a grid, but less so or not at all for participants who had viewed a calendar with.

\section{Experimental Design}

\section{A. Experimental Treatments}

In both dictator game and public goods game, we employed three between-subjects treatments - the isolated frame, the standard frame, and the interrelated frame. The isolated and interrelated frames were manipulated with the procedure from Myrseth and Fishbach (2010). Participants viewed a calendar showing the present month, and the calendar contained either a grid that separated the dates or no such grid (see Appendix A). Moreover, the date of the experiment was highlighted in grey in the gridded calendar, but not in the non-gridded calendar. Because we expected participants who viewed the gridded calendar to adopt a more isolated view of their subsequent choice opportunities, we refer to this treatment as the isolated treatment. Conversely, because we expected participants who viewed the calendar with no grid to adopt a less isolated frame, whereby the choice opportunities would be viewed relatively more related to each other, we refer to this as the interrelated treatment. We denote the third treatment, without a calendar, as the standard treatment.

\footnotetext{
${ }^{5}$ The Rosenbaum scale is further discussed in the Experimental Design section.
} 
To capture individuals' self-control, we used the Rosenbaum Self-Control Schedule (Rosenbaum, 1980). The psychometric scale measures individuals' cognitive skills for exercising self-control in the face of temptation. Each subject is asked to respond to 36 statements using a 6point Likert-scale. ${ }^{6}$ Cognitive skills, such as willpower, have been found to be relatively stable within individuals across time, and thus may be said to represent a personality trait, which we refer to as trait self-control. The Rosenbaum Self-Control Schedule has been externally validated against several criteria, such as coping with seasickness (Rosenbaum and Rolnick, 1983) and saving versus spending (Romal and Kaplan, 1995). Henceforth, we refer the outcome of the Rosenbaum Self-Control Schedule only as the Rosenbaum score.

We expect pro-social behavior to depend on the interaction between identification of self-control conflict (induced by the treatments) and success at the conflict stage (see Figure 1). The isolated treatment yields a lower probability of conflict identification relative to that of other treatments. Hence, trait self-control as measured by the Rosenbaum score is expected to exhibit a weaker correlation with pro-social behavior. In contrast, the interrelated treatment yields a higher probability of conflict identification. Hence, trait self-control is expected to exhibit a stronger positive correlation with pro-social behavior.

\section{B. Games}

We recruited subjects from various undergraduate and graduate classes at three universities in Medellín, Colombia, 2008. For the dictator game, we held six sessions with 18-31 participants per session. Individuals were randomly assigned within a session to one of the three treatments. In the public good game, we held six sessions, two for each of the experimental treatments, with 24-28 participants per session. Individuals were randomly assigned to sessions and thus to treatments. Nobody participated in more than one experimental session, and none were students of mathematics, psychology, or economics.

\footnotetext{
${ }^{6}$ Each statement is graded from -3 to +3 . Thus, "perfect” self-control corresponds to +108 and no self-control at all to -108 .
} 


\section{Dictator Game}

We employed a standard dictator game, designating the Colombian Red Cross as recipient (e.g., similar to Eckel and Grossman, 1996). Average session earnings were 13,000 Colombian Pesos (including a 5,000 Peso show-up fee). ${ }^{7}$ A receipt of the donations was posted on a bulletin board within five days of the completed session in the building adjacent to that in which the experiment was conducted. ${ }^{8}$ A session lasted on average about one hour.

\section{Public Goods Game}

We employed a standard linear public goods experiment. Each group consisted of four members. Each member was endowed with 20 tokens, to be divided between a public and a private good. The payoff for member $i$, measured in units of tokens, was calculated according to the payoff function

$$
\pi_{i}=20-c_{i}+0.4 \sum_{i=1}^{4} c_{i},
$$

where $c_{i}$ is member $i$ 's contribution to the public good. The contribution to the public good yielded a marginal return to each member of 0.4 tokens. The choice of parameter values reflects the features of a public good; full contribution to the public good is Pareto optimal, while the dominant strategy is zero contribution. In other words, the dominant strategy is to free-ride.

Our game followed the experimental design of Fischbacher et al. (2001), also used in numerous follow-up studies (e.g., Fischbacher and Gächter, forthcoming). Participants were asked to make both an unconditional and a conditional contribution to the public good. In the case of unconditional contributions, they were simply asked how much they would like to contribute to the public good (as in a standard public goods game). In the case of conditional contributions, participants were asked how much they would like to contribute conditional on the

\footnotetext{
${ }^{7}$ The exchange rate at the time of the experiment was approximately 1 USD=1,762.00 Colombian Pesos.

8 To ensure credibility, invitations to the experiment were done jointly by the experimenters and the head administrator who later posted experimental id numbers, and their respective donations, as well as the total amount donated to the Red Cross Colombia. This procedure was outlined as part of recruitment as well as in the instructions.
} 
average contribution of other group members, the contribution of which ranged from 0 to 20, rounded to the nearest integer. Participants were randomly assigned to groups of four (from the same session). ${ }^{9}$ To make each decision incentive compatible, the unconditional contribution was the payoff-relevant decision for three randomly selected members. Using their average unconditional contribution, the contribution of the fourth member was given by her conditional contribution table. Then, each member's monetary payoff is computed by equation (1). Each token in the experiment was exchanged for 750 Colombian Pesos. The average earnings per participant were 25,000 Colombian pesos (including a 5,000 show-up fee). A session lasted about 1.5 hours.

\section{Results}

\section{A. Dictator Game}

In table 1, we summarize the descriptive results from the dictator game. We cannot based on a Kruskal-Wallis test reject the null hypothesis of no difference in donations across treatments. Similarly, we cannot reject the null hypothesis of no difference in Rosenbaum score across treatments. This implies that participants in the three treatments had the same level of trait selfcontrol.

\section{(Table 1)}

We hypothesized that participants' trait self-control, as measured by the Rosenbaum score, would exhibit a stronger positive correlation with charitable giving in the interrelated treatment; participants in the interrelated treatment more likely would identify self-control conflict than would participants in the other two treatments. We tested this hypothesis with an OLS regression, and we report the results in table 2. We included an interaction between the Rosenbaum and the dummy variable identifying the interrelated treatment, but we did include not the dummy variable alone; the interrelated treatment represented the baseline treatment. We also included two dummy variables to identify the treatments (the isolated treatment and the standard treatment) and interaction variables between the Rosenbaum score and dummy variables for each of the other two treatments.

\footnotetext{
${ }^{9}$ The selection was anonymous. Hence no participant knew to which group he/she belonged.
} 
(Table 2)

We expected the sign to be positive on the interaction between the Rosenbaum and the dummy for the interrelated treatment. Furthermore, we predicted that coefficients on the interactions between the Rosenbaum and the other two treatment dummies would be smaller than that on the interaction between the Rosenbaum and the interrelated treatment dummy.

The estimated parameter for the interaction between the interrelated treatment and the Rosenbaum score is positive and significant at the $1 \%$ level. ${ }^{10}$ This means that higher self-control in the interrelated frame is correlated with larger donations. The regression shows that the estimated parameter for the interaction between the isolated treatment and the Rosenbaum is negative and not significant, suggesting a weaker correlation between trait self-control and giving in the isolated than in the interrelated treatment. Moreover, the regression shows that the estimated parameter for the interaction between the standard treatment and the Rosenbaum score is positive and not significant. Taken together, the regression provides evidence for our hypothesis that trait self-control exhibits a stronger positive correlation with donating in the interrelated treatment (calendar without a grid) than in the isolated treatment (calendar with a grid). This effect is of economic significance. The marginal effect of the Rosenbaum score in the interrelated treatment is 0.08 . In the interrelated treatment, a one standard deviation increase in the Rosenbaum score (approximately 33 units in the test score) increases donations by about 1,862 Colombian Pesos. Compared to the predicted mean contribution of 8,688, this corresponds to a $21 \%$ increase in donations relative to the aforementioned baseline.

\section{B. Public Goods Game}

In table 3, we present the descriptive results from the public goods game. We cannot based on a Kruskal-Wallis test reject the null hypothesis of no difference in unconditional contributions across treatments. Similarly, we cannot reject the null hypothesis of no difference in Rosenbaum score across treatments.

(Table 3)

${ }^{10}$ Results are robust also when using Tobit rather than OLS with robust standard errors. 
We hypothesized that participants' trait self-control, as measured by the Rosenbaum score, would exhibit a stronger positive correlation with unconditional contribution in the interrelated treatment; participants in the interrelated treatment more likely would identify selfcontrol conflict than would participants in the other two treatments. We test this hypothesis with an OLS regression, results reported in table 4. We included an interaction between the Rosenbaum and the dummy variable identifying the interrelated treatment, but we did include not the dummy variable alone; the interrelated treatment represented the baseline treatment. We also included two dummy variables to identify the treatments (the isolated treatment and the standard treatment) and interaction variables between the Rosenbaum score and dummy variables for each of the treatments.

(Table 4)

We expected the sign to be positive on the interaction between the Rosenbaum and the dummy for the interrelated treatment. Furthermore, we predicted that coefficients on the interactions between the Rosenbaum and the other two treatment dummies would be smaller than that on the interaction between the Rosenbaum and the interrelated treatment dummy.

As in the dictator game, the coefficient for the interaction between the interrelated treatment and the Rosenbaum is both positive and significant at the 5\%-level, indicating that higher self-control in the interrelated treatment is positively correlated with contribution to the public good. The estimated coefficients for the interaction terms between the isolated and standard treatment are both negative and not significant, suggesting a weaker correlation between trait self-control and contribution in the isolated and standard treatments than in the interrelated treatment. Taken together, the regressions provide evidence for our hypothesis that trait selfcontrol exhibits a stronger positive correlation with contribution to the public good in the interrelated than in the isolated treatment. As with the dictator game, this effect is of economic significance. The marginal effect of the Rosenbaum score in the interrelated treatment is approximately 0.08. In the interrelated treatment, a one standard deviation increase in the Rosenbaum score (approximately 20 units in the test score) increases contributions by about 1,6 
tokens. Compared to the predicted mean contribution of 8.6, this corresponds to an $18 \%$ increase in donations relative to the aforementioned baseline

\section{Discussion}

Our objective was to test the hypothesis that individuals may experience a self-control conflict between acting in the interest of self or in that of others. In so doing, we have explored a hypothesis that would help reconcile conflicting ideas in economics about the selfish Homo Economicus and the pro-social Homo Behavioralis. While the literature to date has documented the existence of both selfish and pro-social preferences (for overview see e.g., Fehr and Schmidt, 2006), we have here explored how individuals may possess both. Indeed, we found evidence that individuals may experience a conflict between their better judgment to act in the interest of others and a temptation to act in that of their own. These findings shore up past evidence from psychology.

To conceptualize the question of selfish versus pro-social behavior as a problem of selfcontrol problem may prove insightful at a number of levels. The literature on self-control is extensive, and it offers a substantial conceptual toolkit. The application of models of intrapersonal conflict (e.g., Thaler and Shefrin, 1981; Schelling, 1984; Fudenberg and Levine, 2006) may advance the study of pro-social behavior. For example, one could imagine application to strategic settings, where the question of pro-social versus selfish behavior determines predicted equilibria. How the "rational self" strategizes against her own impulses, which in part may be determined by the agent's beliefs about others' beliefs, may prove crucial for understanding prosocial outcomes. Furthermore, and at a more practical level, the conceptual toolkit for the study of self-control may provide useful prescriptive measures to facilitate Pareto optimality. The application of self-control strategies, such as commitment devices, may help promote pro-social behavior and thus Pareto optimal allocations. The role of the policy maker, then, may be to help individuals help themselves to help others.

Our findings also reveal that subtle cues in the environment may prove sufficient to alter an individual's perception of an allocation opportunity between oneself and others. The cues may thereby determine the extent to which individuals use their own cognitive resources to promote pro-social behavior. We demonstrated this both in the context of charitable giving using a dictator 
game, and in the context of a social dilemma using a public goods game. We further show that the results are of economic significance. We therefore conclude that relatively costless measures may influence individuals to use their cognitive resources to promote pro-social behavior.

Though we have provided evidence for the conceptualization that temptation to act in the interest of oneself may conflict with better judgment to act in the interest of others, we do not claim universality. Rather, we believe our conceptualization applies in situations where feelings of greed dominate those (if any) to act pro-socially. Of course, as O’Donaghue and Loewenstein (2007) suggest, there is good reason to think that the pattern may reverse in other circumstances. Specifically, when empathetic emotion is particularly strong, individuals may feel tempted to be pro-social even knowing that they ought not. For example, one could imagine a face-to-face interaction with a beggar whom one suspects is a “con," seeking "easy” money. One knows better, but one cannot help yielding to the sorry gestures. Because our present space of inquiry concerned the relationship between self-control and feelings of greed, we deliberately designed our studies to minimize feelings of empathy by keeping the recipient of pro-social behavior highly or moderately abstract (an anonymous group in the public goods game or the Red Cross, respectively). Had the recipient been a lively baby, we would of course have expected a different emotional reaction. Future research may explore the effect of tuning up feelings of empathy while tuning down those of greed. 


\section{References}

Ariely, Dan, Anat Bracha, and Stephan Meier. 2009. “Doing Good or Doing Well? Image Motivation and Monetary Incentives in Behaving Prosocially.” The American Economic Review, 99(1): 544-55.

Baumeister, Roy F., Heatherton, Todd F., and Dianne M. Tice. 1994. Losing Control: How and Why People Fail at Self-Regulation. San Diego, CA: Academic Press.

Bénabou, Roland, and Jean Tirole. 2006. "Incentives and Prosocial Behavior.” The American Economic Review, 96(5): 1652-78.

Burger, Nicholas, Gary Charness, and John Lynham. 2009. “Three Field Experiments on Procrastination and Willpower." http//:www.econ.ucsb.edu/ charness/papers/study_010809.pdf.

Curry, Oliver S., Michael E. Price, and Jade G. Price. 2008. “Patience is a Virtue: Cooperative People Have Lower Discount Rates.” Personality and individual differences, 44(3): 780-85.

Eckel, Catherine C., and Philip J. Grossman. 1996. “Altruism in Anonymous Dictator Games.” Games and Economic Behavior, 16(2): 181-91.

Fehr, Ernst, and Klaus M. Schmidt. 2006. “The Economics of Fairness, Reciprocity and Altruism - Experimental Evidence and New Theories.” In Handbook on the Economics of Giving, Reciprocity and Altruism, eds. Kolm, Serge-Christophe, and Jean Mercier Ythier, 615-91. Amsterdam: Elsevier.

Fischbacher, Urs, Simon Gächter, and Ernst Fehr. 2001. “Are People Conditionally Cooperative? Evidence from a Public Goods Experiment.” Economics Letters, 71, 397404.

Fischbacher, Urs, and Simon Gächter. Forthcoming. "Social Preferences, Beliefs and the Dynamics of Freeriding in Public Good Experiments.” The American Economic Review.

Fudenberg, Drew, and David Levine. 2006. “A Dual-Self Model of Impulse Control.” The American Economic Review, 96(5): 1449-76.

Laibson, David I. 1997. “Golden Eggs and Hyperbolic Discounting.” Quarterly Journal of Economics, 112(2): 443-77. 
Kahneman, Daniel, Jack L. Knetsch, and Richard H. Thaler. 1986. "Fairness and The Assumptions of Economics.” Journal of Business, 59(4): 285-300.

Kahneman, Daniel, Jack L. Knetsch, and Richard H. Thaler. 1986. "Fairness as a Constraint on Profit-Seeking: Entitlements in the Market.” The American Economic Review, 76(4): 728-741.

Loewenstein, George. 1996. “Out of control: Visceral Influences on Behavior.” Organizational Behavior and Human Decision Processes, 65(3), 272-92.

Loewenstein, George. 2000. "Preferences, behavior and welfare: Emotions in Economic Theory and Economic Behavior.” The American Economic Review, 90(2): 426-32.

Myrseth, Kristian O. R., and Ayelet Fishbach. 2009. "Self-Control: A Function of Knowing When and How to Exercise Restraint.” Current Directions in Psychological Science. 18(4): 247-52.

Myrseth, Kristian O. R., and Ayelet Fishbach. 2010. "Seeing Self-Control Conflict: The Problem of Isolated versus Interrelated Temptations.” Unpublished.

O’Donoghue, Ted, and George Loewenstein. 2007. The Heat of the Moment: Modeling Interactions Between Affect and Deliberation.” http//:www.arts.cornell.edu/econ/edo1/heat.pdf

O’Donoghue, Ted, and Matthew Rabin. 1999. “Doing it Now or Later?” The American Economic Review, 89(1): 103-24.

Plato. 1986. “Protagoras.” In The Dialogues of Plato, Trans. Anthony F. Hubbard and Ellen S. Karnofsky, New York: Bantam Books. (Orig. pub. 380 B. C.).

Pronin, Emily, Cristopher Y. Olivola, and Kathleen A. Kennedy. 2008. "Doing Unto Future Selves as You Would Do Unto Others: Psychological Distance and Decision Making.” Personality and Social Psychology Bulletin, 34(2): 224 - 36.

Romal, Jane B., and Brian J. Kaplan. 1995. “Differences in Self-Control among Spenders and Savers.” Psychology: A Journal of Human Behavior, 32(2): 8 -17.

Rosenbaum, Michael. 1980. “A Schedule for Assessing Self-Control Behaviors: Preliminary Findings.” Behavior Therapy , 11(1): 109-21.

Rosenbaum, Michael, and Arnon Rolnick. 1983. "Self-Control Behaviors and Coping with Seasickness.” Cognitive Therapy and Research, 7(1): 93 - 97. 
Schelling, Thomas. 1984. "Self-Command in Practice, in Policy, and in a Theory of Choice." The American Economic Review, 74(2): 1-11.

Thaler, Richard H. and Hersh M. Shefrin. 1981. “An Economic Theory of Self-Control.” The Journal of Political Economy, 89(2): 392-406. 
Table 1. Descriptive statistics - the dictator game

\begin{tabular}{|c|c|c|c|c|c|c|c|}
\hline \multirow[b]{2}{*}{ Variable } & \multicolumn{2}{|c|}{ Isolated treatment } & \multicolumn{2}{|c|}{ Standard treatment } & \multicolumn{2}{|c|}{ Interrelated treatment } & \multirow{2}{*}{$\begin{array}{c}\text { HO: No } \\
\text { difference } \\
\text { between } \\
\text { treatments } \\
\text { (Kruskal- } \\
\text { Wallis p) }\end{array}$} \\
\hline & Obs & Mean & Obs & Mean & $\overline{\text { Obs }}$ & Mean & \\
\hline Donation & 51 & $7892.16(4158.50)$ & 49 & 8321.43 (4608.642) & 46 & 8691.30 (4959.91) & 0.646 \\
\hline $\begin{array}{l}\text { Rosenbaum } \\
\text { score }\end{array}$ & 47 & 35.85 (25.73) & 48 & 34.04 (24.54) & 45 & 33.13 (23.12) & 0.777 \\
\hline
\end{tabular}

Note. Standard deviations in parentheses 
Table 2. Estimation results - the dictator game.

\begin{tabular}{lc}
\hline \hline Dep. var: Donation in 1,000 & OLS \\
\cline { 2 - 2 } Isolated treatment & Coef. \\
Standard treatment & 2.28 \\
& $1.49)$ \\
Rosenbaum score x Isolated & $(0.78)$ \\
treatment & -0.01 \\
& $(-0.42)$ \\
Rosenbaum score x & 0.03 \\
Standard treatment & $(1.13)$ \\
& $0.08 * * *$ \\
Rosenbaum score $x$ & $(2.98)$ \\
Interrelated treatment & $6.02^{* * *}$ \\
Constant & $(6.61)$ \\
& 140 \\
Number of observations & 0.07 \\
R-squared & \\
\hline Note: *** denotes significance at the 1\% level, ** at the \\
5\% significance level, * at the 10\% significance level. \\
Note: the regression controls for the university where \\
sessions were run but the result isomitted; t-statistics in \\
parenthesis; robust standard errors.
\end{tabular}


Table 3. Descriptive statistics - the public goods game

\begin{tabular}{|c|c|c|c|c|c|c|c|}
\hline \multirow{3}{*}{$\begin{array}{l}\text { Variable } \\
\text { Unconditional } \\
\text { contribution } \\
\text { Rosenbaum }\end{array}$} & \multirow{2}{*}{\multicolumn{2}{|c|}{$\begin{array}{cc}\begin{array}{c}\text { Isolated } \\
\text { treatment }\end{array} \\
\text { Obs }\end{array}$}} & \multirow{2}{*}{\multicolumn{2}{|c|}{$\begin{array}{c}\begin{array}{c}\text { Standard } \\
\text { treatment }\end{array} \\
\text { Obs Mean }\end{array}$}} & \multicolumn{2}{|c|}{$\begin{array}{c}\text { Interrelated } \\
\text { treatment }\end{array}$} & \multirow{2}{*}{$\begin{array}{c}\text { HO: No } \\
\text { difference } \\
\text { between } \\
\text { tratments } \\
\text { (Kruskal- } \\
\text { Wallis p) }\end{array}$} \\
\hline & & & & & Obs & Mean & \\
\hline & 56 & 8.05 (6.28) & 47 & 7.68 (5.96) & 53 & 8.72 (6.61) & 0.73 \\
\hline Score & 55 & 31.51 (20.32) & 48 & 27.98 (19.70) & 51 & 29.41 (19.86) & 0.7 \\
\hline
\end{tabular}

Note. Standard deviations in parentheses 
Table 4. Estimation results - the public good game.

\begin{tabular}{lc}
\hline \hline Dep. var: Unconditional & OLS \\
\cline { 2 - 2 } contribution in tokens & Coef. \\
\hline Isolated treatment & $(1.23$ \\
& 1.99 \\
Standard treatment & $(1.01)$ \\
& -0.05 \\
Rosenbaum score x Isolated & $(-1.03)$ \\
treatment & -0.02 \\
& $(-0.57)$ \\
Rosenbaum score x & $0.08 * *$ \\
Standard treatment & $(1.98)$ \\
& 6.34 \\
Rosenbaum score x & $(4.52)$ \\
Interrelated treatment & 153 \\
& 0.04 \\
Constant & \\
Number of observations & \\
R-squared & Note: $* * *$ denotes significance at the $1 \%$ \\
\hline 5\% significance level, * at the 10\% significance level. \\
Note: the regression controls for the university where \\
sessions were run but the result isomitted; t-statistics in \\
parenthesis
\end{tabular}


Figure 1. The two-stage model of self-control.

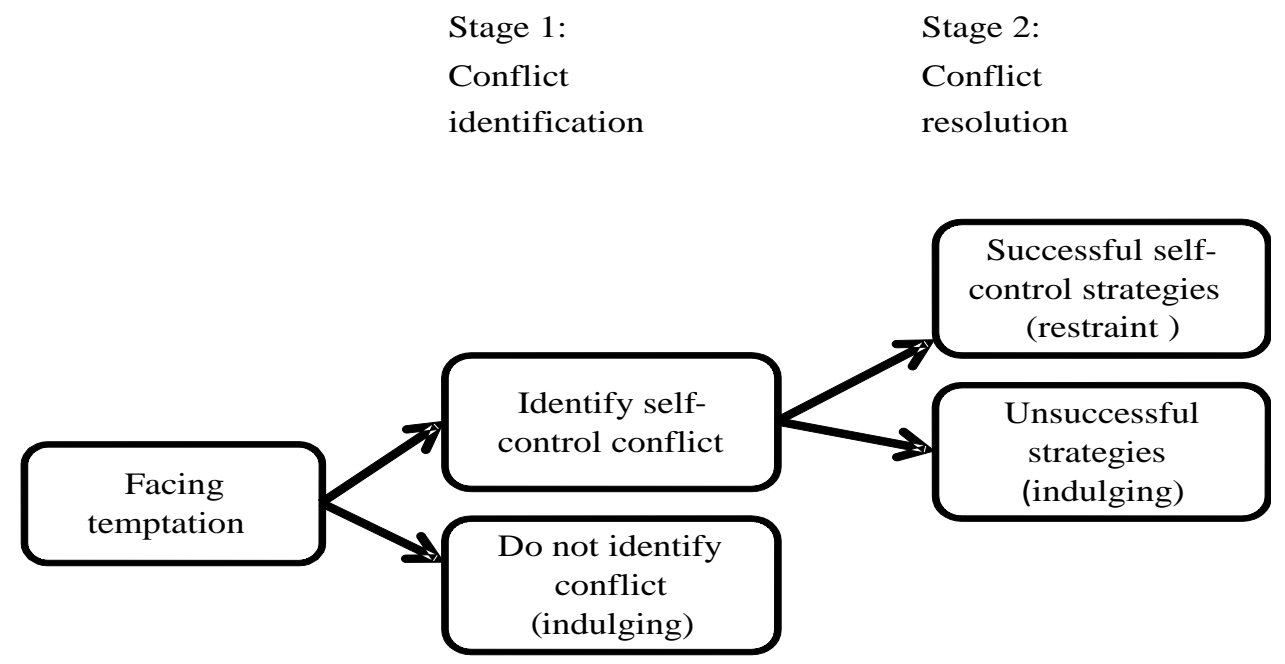

Source: Myrseth and Fishbach (2009). 


\section{Appendix A: Calendars}

A.1 The isolated frame (the highlighted date is the same as today's date).

Before we continue with the experiment, please take a moment to consider this month's calendar:

\begin{tabular}{|c|c|c|c|c|c|c|}
\hline Sun & Mon & Tue & Wed & Thu & Fri & Sat \\
\hline 4 & 5 & 6 & 7 & 8 & 9 & 10 \\
\hline 11 & 12 & 13 & 14 & 15 & 16 & 17 \\
\hline 18 & 19 & 20 & 21 & 22 & 23 & 24 \\
\hline 25 & 26 & 27 & 28 & 29 & 30 & 31 \\
\hline
\end{tabular}

What is today's date? 
A.2 The interrelated frame.

Before we continue with the experiment, please take a moment to consider this month's calendar:

\begin{tabular}{|ccccccc|}
\hline Sun & Mon & Tue & Wed & Thu & Fri & Sat \\
& & & & 1 & 2 & 3 \\
4 & 5 & 6 & 7 & 8 & 9 & 10 \\
11 & 12 & 13 & 14 & 15 & 16 & 17 \\
18 & 19 & 20 & 21 & 22 & 23 & 24 \\
25 & 26 & 27 & 28 & 29 & 30 & 31 \\
\hline
\end{tabular}

What is today's date? 